http://jmscr.igmpublication.org/home/ ISSN (e)-2347-176x ISSN (p) 2455-0450

crossref DOI: https://dx.doi.org/10.18535/jmscr/v9i11.12

\title{
Case report of Encorporesis as a rare presenting symptom in Attention deficit hyperkinetic disorder in adolescent male
}

\author{
Authors \\ Dr Teeba Salwan Abbood ${ }^{1}$, Dr Budoor Kahtan Al Shammari ${ }^{2}$ \\ ${ }^{1}$ MBBS /Family Medicine Specialist \\ ${ }^{2} \mathrm{MBBCH} /$ Pediatrics Specialist \\ Primary Health Care, Doha, Qatar
}

\section{Introduction}

Many studies have shown that behavioral problems are associated with defecation and voiding disorders, nevertheless few studies have looked directly at a link between a diagnosis of attention-deficit/hyperactivity disorder (ADHD) and constipation or fecal incontinence. ${ }^{1}$

Keywords: ADHD, Encorporesis

\section{Case Presentation}

11 year old boy presented to our health Centre on October 2021 with mother who gave the details of his history as he was born in his home country via normal vaginal delivery with unremarkable perinatal history Up To Date vaccine record the mother raised a concern of recurrent balanitis.

Periodic balanitis was treated successfully with every visit which was as frequent as 3 times a year Further digging into details of the history was the patient never achieved toilet training for the stool patient physical examination was unremarkable.

A journey of full investigation of his blood/stool/hormonal profile with unremarkable results

Further imaging revealed totally normal structure with no neurological insult or disorders.
Patient was given primary encopresis non retentive diagnosis.

And was referred to pediatric psychiatry consultation who inquire about detailed behavioral history and concluded that the patients is having ADHD with the only prominent uncommon association for this disorder is the current encopresis

Fully detailed discussion of the conditions was explained to the parents pharmacological medication was offered yet the limitation of the medication in controlling or improving the current symptoms was discussed and referred for behavioral therapy with regular follow ups with pediatric clinic.

\section{Discussion}

Fecal incontinence, also known as encopresis or soiling, refers to the repetitive, voluntary or involuntary, passage of stool in inappropriate places by children four years of age and older, at which time a child may be reasonably expected to have completed toilet training and exercise bowel control.

Fecal incontinence usually is related to underlying constipation $^{[2]}$. In many cases, the constipation is 
well recognized before the child presents with fecal incontinence. In other cases, the underlying constipation is not recognized by the family and is only identified after a focused history and physical examination is performed. Treatment of fecal incontinence differs depending on the presence or absence of underlying constipation.

Many studies have been shown that behavioral problems are associated with defecation and voiding disorders, however few studies have looked directly at a link between a diagnosis of attention-deficit/hyperactivity disorder (ADHD) and constipation or fecal incontinence. ${ }^{1}$

Constipation and fecal incontinence usually coexist and with such symptoms can be frustrating for all of the patients, parents, and physicians. These conditions also lead to recurrent doctors' visits, excessive health care utilization costs, and may also detrimentally affect quality of life. ${ }^{3-5}$ however Functional constipation in children is multifactorial, usually developing from a combination of a diet low in fiber and behavioral withholding of stool. ${ }^{6}$

Physicians who are experienced in the treatment of constipation in children know that management of the behavioral aspects of constipation are as important as the medical and dietary aspects. ${ }^{7}$

No much studies have evaluated the relationship between pediatric constipation, fecal incontinence, and other behavioral, psychological, or emotional disorders. In 1966, Bellman ${ }^{8}$

one study has reported that 75 boys with the diagnosis of fecal incontinence were more likely to demonstrate school disturbances. In 1984, Abrahamian and Lloyd-Still ${ }^{9}$

And $20 \%$ of children with chronic constipation had "significant psychological problems on the basis of behavior problems at home or at school." Studies that have used the Child Behavior Checklist or other similar questionnaires to evaluate behavioral or other emotional problems have associated higher (more severe) behavioral scores with constipation, fecal incontinence, and voiding. ${ }^{10-12}$
Most recently in 2013, Peeters et al $^{13}$ Reported that a large number of children presenting with defecation disorders also fall into the autism spectrum disorder.

Attention-deficit/hyperactivity disorder (ADHD) is a problem in which children exhibit inattentiveness, overactivity, impulsivity, or difficulty focusing. ADHD is also the most commonly diagnosed behavioral disorder of childhood. $^{14}$

Evaluation of an association between the diagnosis of ADHD and defecation disorders, such as constipation and fecal incontinence by studies are rare.

Generally speaking Encopresis is a common pediatric disorder with an average prevalence around $4.1 \%$ among 5 to 6 year-old and in $1.6 \%$ among 11- 12year-old children.1 Attention deficit hyperactivity disorder

(ADHD) is among the most frequently reported coexisting psychiatric conditions in children with encopresis. ${ }^{(2)}$ yet not a major presenting symptom in addition to that ,Both ADHD and encopresis have been shown to have a wide range of adverse effects on psychosocial functioning. ${ }^{(15)}$

Newest case reports state that atomoxetine-a selective presynaptic norepinephrine reuptake inhibitor-approved for treatment of ADHD is also effective in the treatment of coexisting encopresis. $^{(16,17)}$

However, the authors of those studies reported that the effect of atomoxetine onencopretic symptoms is not known. They claimed that it might be related to its direct peripheral effects on gastrointestinal system (GIS) via increased noradrenaline levels and sympathetic activity. ${ }^{(18)}$ Contrasting those reports, here we present a case diagnosed with ADHD and secondary encopresis without constipation whose encopretic symptoms increased after atomoxetine treatment and discuss possible mechanisms.

However in other case report it was shown that Increased Frequency of Encopresis in a child diagnosed with Attention Deficit/Hyperactivity Disorder and encopresis after atomoxetine Use ${ }^{(19)}$ 
Conflict of Interest: None

Funding: None

\section{References}

1. Rasquin A, Di Lorenzo C, Forbes D, et al.. Childhood functional gastrointestinal disorders: child/adolescent. Gastroenterology. 2006;130(5):15271537.

2. Loening-Baucke V. Prevalence rates for constipation and faecal and urinary incontinence. Arch Dis Child 2007; 92:486.

3. Liem O, Harman J, Benninga M, Kelleher $\mathrm{K}$, Mousa H, Di Lorenzo C. Health utilization and cost impact of childhood constipation in the United States. J Pediatr. 2009;154(2):258-262 [PubMed] [Google Scholar]

4. Wald A, Sigurdsson L. Quality of life in children and adults with constipation. Best Pract Res Clin Gastroenterol. 2011;25 (1):19-27 [PubMed] [Google Scholar]

5. Rajindrajith $S$, Devanarayana NM, Benninga MA. Review article: faecal incontinence in children: epidemiology, pathophysiology, clinical evaluation and management. Aliment Pharmacol Ther. 2013;37(1):37-48

6. Rajindrajith S, Devanarayana NM. Constipation in children: novel insight into epidemiology, pathophysiology and management. J Neurogastroenterol Motil. 2011;17(1):35-47.

7. Di Lorenzo C. Childhood constipation: finally some hard data about hard stools! J Pediatr. 2000;136(1):4-7

8. Bellman M. Studies on encopresis. Acta Paediatr Scand. 1966;(suppl 170):1. [PubMed] [Google Scholar]

9. Abrahamian FP, Lloyd-Still JD. Chronic constipation in childhood: a longitudinal study of 186 patients. J Pediatr Gastroenterol Nutr. 1984;3(3):460-467 [PubMed] [Google Scholar]
10. Benninga MA, Voskuijl WP, Akkerhuis GW, Taminiau JA, Büller HA. Colonic transit times and behaviour profiles in children with defecation disorders. Arch Dis Child. 2004;89(1):13-16 [PMC free article] [PubMed] [Google Scholar]

11. Duel BP, Steinberg-Epstein R, Hill M, Lerner M. A survey of voiding dysfunction in children with attention deficithyperactivity disorder. J Urol. 2003;170(4 pt 2):1521-1523, discussion 1523-1524 [PubMed] [Google Scholar]

12. Becker A, Rubly M, El Khatib D, Becker $\mathrm{N}$, von Gontard A. Central nervous system processing of emotions in children with faecal incontinence. Acta Paediatr. 2011;100(12):e267-e274 [PubMed] [Google Scholar]

13. Peeters B, Noens I, Philips EM, Kuppens S, Benninga MA. Autism spectrum disorders in children with functional defecation disorders. J Pediatr. 2013; 163(3):873-878 [PubMed] [Google Scholar]

14. Wolraich M, Brown L, Brown RT, et al. Subcommittee on AttentionDeficit/Hyperactivity Disorder. Steering Committee on Quality Improvement and Management . ADHD: clinical practice guideline for the diagnosis, evaluation, and treatment of attention-deficit/hyperactivity disorder in children and adolescents. Pediatrics. 2011;128(5):1007-1022 [PMC free article] [PubMed] [Google Scholar]

15. Mellon MW, Natchev BE, Katusic SK, et al. Incidence of enuresis and encopresis among children with attentiondeficit/hyperactivity disorder in a population-based birth cohort. Acad Pediatr 2013;13:322-327.

16. Hergüner S, Hergüer A. Atomoxetine for encopresis in 2 children with attentiondeficit/hyperactivity disorder. J Clin Psychopharmacol 2012;32:302-303. 
17. Yücel A, Yücel N, Oral E. The Role of Atomoxetine and Sympathetic Pathways in Encopresis with ADHD. Bulletin of Clinical Psychopharmacology 2015; 25(1):93-94

18. Yücel A, Yücel N, Oral E. The Role of Atomoxetine and Sympathetic Pathways in Encopresis with ADHD. Bulletin of Clinical Psychopharmacology 2015;25(1):93-94

19. Çiğdem Yektaş, MD, ${ }^{*}$ Mehmet Akif Cansız, MD, $\uparrow$ and Ali Evren Tufan, MD $\dagger$ 